\title{
Public service markets: their economics, institutional oversight and regulation
}

\author{
Xeni Dassiou', Peter Langham², Charles Nancarrow ${ }^{2}$, Alex Scharaschkin ${ }^{3}$ and Dan Ward ${ }^{4}$
}

\begin{abstract}
Public services in the United Kingdom have been transformed over the past 25 years with the introduction of market-oriented solutions into their provision. This has been characterized by a shift away from state provision to independent providers, and by the introduction of competition and choice. This shift was partly ideologically motivated and partly driven by budget-cutting considerations following the global financial crisis. As such, it has been lacking a comprehensive economic justification or method of analysis. It is now commonly accepted that the language of economic markets is essential to frame arguments about how effectively public services are achieving their intended outcomes. Using market language and concepts may not always be comfortable for those from a traditional policymaking background. It can nevertheless be very useful when designing investigations into the effectiveness and value for money in the mechanisms of delivery of such services, whenever these services entail a degree of user choice as is currently the case in large parts of health care, social care and education (referred to as competition in the market). This article aims to provide a conceptual basis on the way of thinking in these terms. We provide a description of the current state and then comment on the desirability of this quasi-market approach. Uniquely in the literature, we analyse the expected and desired developments by distinguishing between choice and compulsory merit goods. In choice merit goods markets many users are unable to choose effectively because of the existence of a number of demand-side or supply-side market failures. Moreover, conflicts may exist between how service users actually make choices, and policy objectives such as universality or equity, which may not be achieved simply by "leaving it to the market". The users of compulsory merit goods are typically a minority and unable to internalize the full social benefits of their actions; hence, it may be welfare-enhancing for society to coerce them to "consume" these services. As choice cannot be an objective, the commissioning (competition for the market) or direct provision by the state of such goods may meet public policy objectives more effectively than the market mechanism alone. Building on these foundations, this article discusses when public service markets (PSMs) are likely to be an effective method of achieving public policy objectives, and when they may not be. We analyse the implications for the institutional and legal framework, funding oversight and regulation of PSMs as a result of their transformation into quasi-markets. We conclude with some suggestions for those charged with overseeing PSMs in practice based on this analysis.
\end{abstract}

\footnotetext{
${ }^{1}$ Department of Economics, City University London, London, UK ${ }^{2}$ National Audit Office, London, UK ${ }^{3}$ Centre for Education Research and Practice, AQA, London, UK ${ }^{4}$ NHS Monitor, London, UK. Correspondence: (e-mail: x.dassiou@city.ac.uk)
} 


\section{Introduction}

$\mathrm{n}$ the case of utilities, the goods are typically well defined in their characteristics, and hence price and output decisions are the result of demand and supply market forces, except for a few price regulated monopolies. However, the companies in such industries have an interest in creating artificial complexity in the hope of creating switching costs through the introduction of complex bundle tariffs as in energy, mobile telecoms and so on, which give rise to menu and search costs. Such moves are designed by companies to impede effective competition by creating consumer inertia and relying on loss aversion, framing and other consumer behavioural biases to restrict the consumers' ability to "access, assess and act" on information (a phrase coined by Fletcher, 2013).

In the early years of deregulation in utilities, as the user is typically the payer, well-established techniques of price cap setting (for example, RPI-X) were in place in these market segments where competition was not yet effective to avoid monopoly power abuse of buyers by sellers. The segments where this still applies today are the infrastructure segments with natural monopoly characteristics such as transmission or distribution companies in energy; typically the buyers in such price regulated segments are not the end users, but upstream and downstream companies. Vertical unbundling and technological change have made possible the removal of natural monopoly characteristics in many segments of the value chain. Thus market failure in utilities was eliminated, and with it the main case for regulation. As effective competition flourished, price caps were removed in markets such as retail gas and electricity, generation, telecoms and so on, while the role of the regulator has evolved to one of both providing information to the customers to alleviate their information asymmetries by enabling them to make effective choices, and enforcing competition using concurrent competition powers.

The nature of the "goods" that are "traded" in public service markets (PSMs) is often very different from those in many private and utilities markets, as the former are typically merit goods whose users do not fully internalize the social benefits of their choices and where the user-pays principle does not always apply (Dassiou et al., 2015, forthcoming). Unlike utilities, many of these services are either free at the point of delivery (for example, health) or fixed (for example, universities), thus removing price signals. These markets, coined by Le Grand (1991) as quasimarkets, have been opened up to the "market mechanism" through the introduction of competition and user choice over the last 25 years. There is an extensive literature that reports on the results of such changes. Indicatively, in education Glennerster (1991) comments on the introduction of quasi-markets reforms and Bradley and Taylor (2002) on the implications of these reforms on efficiency and equity. More recently, Bradley and Taylor (2010) examine the impact on exams performance of quasi-market reforms (competition, parental choice, market concentration and the introduction of specialist schools). Lubienski (2009) reviews the impact of the introduction of more autonomy, competition and choice on innovation in education in OECD countries. In health, Propper $(1995,2012)$, Propper et al. (2004, 2008), Propper and Venables (2013) discuss on the initial focus in reducing waiting times and its detrimental effects on unobservable quality and the subsequent abolition of internal market price competition in elective care and shift to increasing hospital choice by allowing more competition among providers. Doetter and Götze (2011) comment on the introduction of the internal market and competition during the 90 s followed by the re-assertion of the state in financing and the regulation of quality in the 2000s. According to Gaynor et al. (2012), as of 2008 there has been a policy shift with the focus on quality-based competition, and the shifting of responsibility for commissioning care to general practitioners (GPs).

PSMs constitute a significant part of government expenditure. According to Fig. 1 (data sourced from ukpublicspending.co. uk), the share of UK's government expenditure peaked to just over $45 \%$ of the GDP in 2010 and is planned to decline to $40 \%$ in 2016. Figures 2, 3 and 4 give the share of health care, education and welfare (including family and children, unemployment, housing payments, social exclusion, social protection and $R \& D$ social protection) in government spending during the last 30 years. We see that health-care spending has hovered to around $7.5 \%$ during the last few years, education has declined from $6 \%$ to just over $5 \%$ with plans to further reduce it in the coming years, while welfare has been reduced from $7.3 \%$ in 2010 to $6.5 \%$ in 2014 with a further planned reduction to $6 \%$ in 2016 . These trends are also easy to see in Table 1 (Eurostat data). These figures reflect the current government's policy of ring fencing spending on health care from spending cuts, keeping education spending constant in nominal terms and reducing welfare spending. According to figures from 2012 (OECD, 2015), the number of teaching staff at all levels of education was just over 900,000 , while there are 1.3 million staff working for over 1,000 different employers for the National Health Service (NHS) (http://hee.nhs.uk/work-programmes/workforceplanning/, accessed 22 September 2015). In social care the

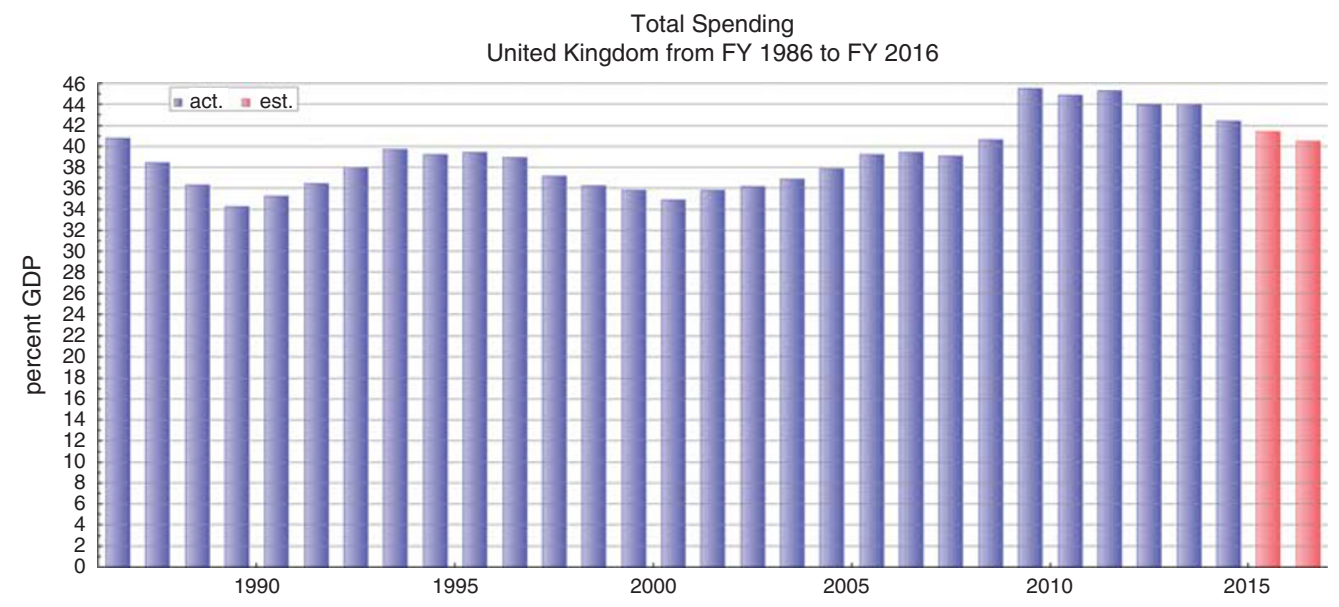

Figure 1 | Total spending in the United Kingdom from FY 1986 to 2016. 


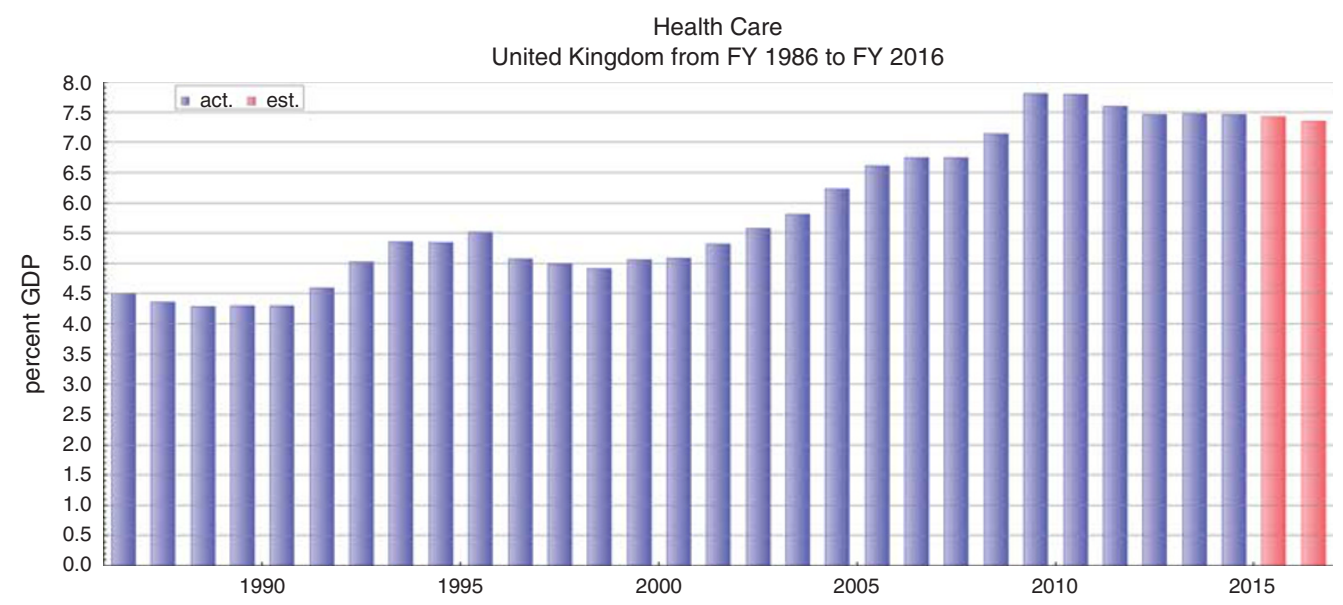

Figure 2 | Total spending on health care in the United Kingdom from FY 1986 to 2016.

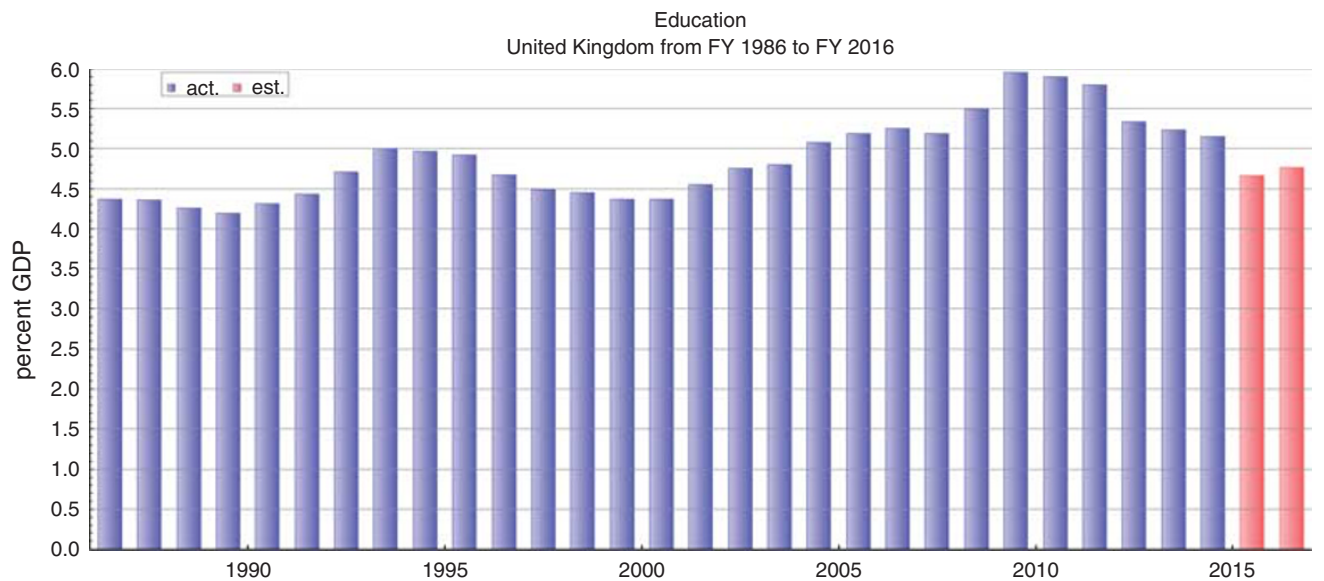

Figure 3 | Total spending on education in the United Kingdom from FY 1986 to 2016.

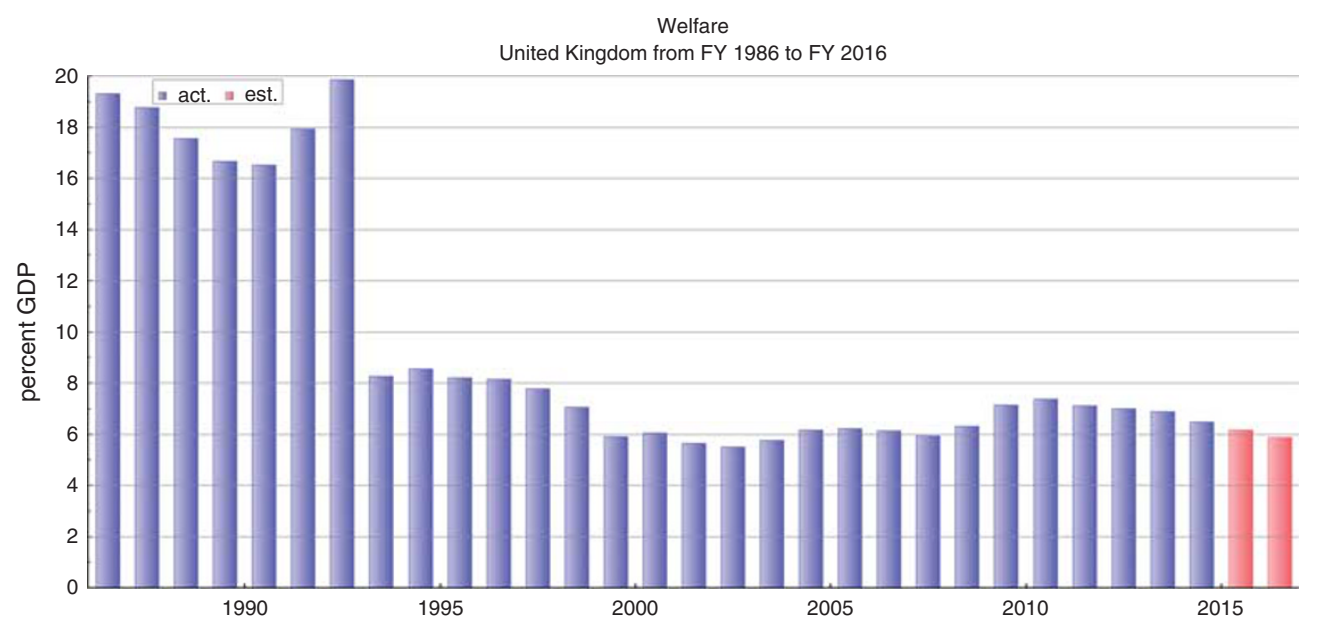

Figure 4 | Total spending on welfare from FY 1986 to 2016.

number of people in adult social care jobs in England was estimated at 1.50 million in 2012. Since 2009 employees have continued to shift away from local authority services $(-15 \%)$ and towards independent employers $(+15 \%)$, while the number of people receiving direct payments to purchase their care has increased by $50 \%$ (http://www.skillsforcare.org.uk/Document-library/NMDSSC,-workforce-intelligence-and-innovation/Research/Size-and-structure2013-vweb2.pdf, accessed 22 September 2015). 


\begin{tabular}{|c|c|c|c|c|}
\hline & 2000 & 2005 & 2010 & 2013 \\
\hline Public order and safety & 5.5 & 5.7 & 5.2 & 4.8 \\
\hline Health & 14.3 & 15.4 & 16.1 & 16.7 \\
\hline Education & 13.0 & 13.5 & 13.5 & 12.0 \\
\hline Sickness and disability & 6.7 & 6.2 & 5.8 & 6.2 \\
\hline Family and children & 4.8 & 6.4 & 4.8 & 3.7 \\
\hline
\end{tabular}

The creation of PSMs has intensified or given rise to a number of market failures that may justify state or regulatory intervention: ${ }^{1}$ some are features of the characteristics of the service or of the users (that is, the demand side), while others are a product of the supply side. These are explained in the sections "Demand-side market failures" and "Supply-side market failures" where we use market definition analysis, a core tool in competition economics for evaluating the strength of competition in markets. ${ }^{2}$ In the section "Overseeing PSMs", we analyse when PSMs are likely to be an effective method of achieving public policy objectives, and when they may not be and conclude with some suggestions for what this all means for those charged with overseeing, managing and regulating these markets in practice. We set out our conclusions in the final section.

\section{Demand-side market failures}

Merit goods. Services are typically merit goods, that is, characterized by large positive externalities in their consumption. Economic theory identifies this as a clear market failure that justifies government intervention. ${ }^{3}$

Education, health and social care are typical examples of "choice" merit goods (case example - Box 1) where, while the good is not public (that is, the service is both rival and excludable), the marginal social benefit of the service significantly exceeds the marginal private benefit. Of course, there are some distinct types of health care that may require some compulsion in their consumption (for example, the need to inoculate the population to protect them from a dangerous communicative disease), or choice is impossible (ambulance and $\mathrm{A} \& \mathrm{E}$ services), or the need to make parents send their children to school.

These goods are such that while state funding is justified to avoid under consumption, in principle there is no reason why the state could not just hand vouchers or direct payments to users and let them choose a supplier, if they are in a position to do so effectively. The reason why this does not happen even if we assume hypothetically that all the users had the ability to effectively choose in this manner (plurality of providers, free entry and exit in the market, ability to access, assess and act on information and so on) is that the state may wish to pursue different objectives like fairness, ensuring quality, as well as budget constraint considerations, which will not necessarily be achieved if users choose providers in an unconstrained manner.

The other main category of merit goods that we define in this article is "compulsory" merit goods: these are services where user choice is either not desirable and/or their consumption is not optional. Typically, the majority of citizens in a society do not "consume" these goods/services (for example, they are not the direct beneficiaries), but are strongly affected by the negative externalities caused by their absence, or their underproduction in quantity and/or quality. ${ }^{4}$ For example, goods like probation services, jail services and workplace programmes are tax funded

\section{Box 1 | Case example-social care}

Social care is characterized by positive externalities (a civilized society expects those people needing care and without sufficient financial means to have their care needs met). The private care market caters for those able to pay for their own care; however, left to the market alone, care would be under-consumed leaving very vulnerable people without financial means to fend for themselves, which explains in principle the policy rationale for government funding social care. When users do not pay for a service there is a risk of overconsumption, so government needs a system of gate-keepers (for example, GPs, care professionals) to ensure only eligible recipients receive publicly funded care

and the justification for this lies in the considerable externalities of these services on the majority of the people in a society who are not direct users. The minority who are the direct users of such services may not wish to use them, but the extent of their externalities justifies the need to coerce them to do so (for example, the unemployment benefit takes the form of a jobseeker's allowance).

While private markets may satisfy part of the demand for merit goods, in order for society to reach the optimum level of output provision and avoid under consumption of the good what is required is either:

- Subsidies: The government could give vouchers or assign budgets to families to meet their health and/or education needs; personal budgets or user entitlements now exist in a number of public services. ${ }^{5}$ However, subsidies may not be preferable if the state wants to prevent "undesirable" outcomes stemming from a mismatch between public policy objectives funded by taxpayers' money and the preferences of the users or

- Commissioning: State provision of the good, to ensure the wider social benefits of these services (for example, probation services, work placement services, waste management services). The latter, alongside the existing private provision where it exists (as in health and education, care and so on), should give an outcome closer to the socially optimum, satisfying the wider public policy objectives that the market mechanism alone will not meet, as the users do not internalize the full social benefits of their actions.

Complex, experience goods. While in the case of utilities, the goods and services provided are usually standard products with well-defined physical attributes, in the case of PSMs the goods can be complex and personalized services that are "experience" (or even "credence") goods with different quality attributes and features. For instance, across all types of care, quality is heavily reliant on individual relationships with care workers, and it is therefore difficult to determine the quality of the service before purchase. Box 2 illustrates some of the characteristics of health care that contribute to the difficulty in assessing and measuring the quality of the treatment concerned with certainty.

Moreover by their nature some of these goods are major life decisions with little room for switching in the case of a poor choice (school, university, social care, health care) without significant inconvenience and disruption. In the case of a frail, elderly resident in a care home, their original choice of the care home may have been poor owing to it being made in a hurry and at a time of mental distress. The prospect, however, of switching homes may be too big a disruption for them to even contemplate 


\section{Box 2 | Attributes of some types of health care}

It is often difficult to measure the quality of health care. Many components of a health service that commissioners or patients value are difficult or impossible to measure. Some of the reasons for this can be:

Time lags-For example, a good indicator of the quality of a cancer service would be how many patients survive for 10 years after treatment. But to find this out you have to wait 10 years, by which point the service offered might have changed completely.

Difficulty of establishing a counterfactual-For example, if a patient has an operation and is left in severe pain afterwards, it can be hard to tell if this is due to an unusually bad surgeon or to a good surgeon dealing with an unusually severe injury.

Problems of attribution-The NHS is only one factor affecting a patient's life, and their long-term health outcomes are also affected by things like their lifestyle, their age and their genes.

and the individual effectively becomes "locked in" to that provider. This means that the user/consumer is either:

a not in a position to engage effectively in the market and exercise choice or switch in the normal way because of the problems described above or

b for compulsory merit goods, it is not desirable that the consumer takes a decision as it is preferable that the state decides on the level of consumption and provision (jail services and so on).

Principal-agent issues. Whereas in utility markets the good is purchased by the user who pays the price and the providers meet this demand, in the case of PSMs this is different: the user is not necessarily the buyer of the service (as this may be commissioned on their behalf) and they typically do not pay for it. Choice and competition may exist, or choice may be exercised on behalf of the user by an agent or at least with the advice of an agent say, a GP.

The asymmetry of information in some PSMs is a market failure that gives them similar characteristics to those found in financial services, where consumers take financial decisions with the advice of an intermediary/broker/adviser or more recently comparison websites, to choose financial products, for example, mortgages, personal pensions, ISAs and so on. The problem is whether the agent (say, the GP in health care) is incentivized in such a way so as to promote the interests of the principal, who is in this case the service user. The position is further compounded by the dual role of the GP as a budget holder and a prescriber of the most appropriate treatment. ${ }^{6}$ The type of provider can also play a role as well: for example, the raison d'etre of a mutual company is the promotion of the customers' interests, thus alleviating problems of asymmetric information between users and providers. We discuss this further below.

Even in the cases where the user does exercise choice by purchasing the service directly and without an agent (this may take the form of an ear-marked budget or vouchers), the user's choice is restricted by the funding for the service from the relevant local authority. For example, with school choice it would be more accurate to say that the user (the parent) can state a preference rather than being able to exercise the right to choose which school their child attends. Hence, the choice of available school places are restricted by how many schools there are in the area, as well as the capacity of these schools. Moreover, it is restricted by what the user considers as substitutes, which may be:

- the result of geographical considerations (proximity);
- the way funding is provided as we have seen in the case of vouchers used in schools in Scandinavia, which may broaden the market definition to include the private sector; or

- the result of substantial price changes as we have seen in the case of universities' market definition slowly evolving from national to international, ${ }^{7}$ or regulatory constraints (for example, school catchment areas, GP registration restrictions and so on). We return to the market definition issues in PSMs below.

Similarly to financial services regulation, asymmetric information between the buyers and the sellers gives rise to both adverse selection (where buyers do not have full information regarding the quality of the goods they purchase) and moral hazard. A demonstration of the latter can be found in the spectacular collapse of many of the providers in the financial industry that were bailed out by the government during the economic crisis. In the case of PSMs, where assets are owned by independent organizations rather than government there is a risk of moral hazard whereby failed organizations can exploit public demand for service continuity by demanding bail outs or excessive returns for investment.

Overconsumption. Unlike utilities markets, many of the quasimarkets are characterized by extensive tax-funded provision. Hence, there is a need for gate keepers to avoid overconsumption when excludability is difficult to enforce and the user does not pay. For example, a GP is not only a provider of information (intermediary), but also a gatekeeper and budget holder to the health system. This means that as an agent he may face conflicting incentives in his dual role, unless incentives are properly set to correct this.

Interestingly, referral by a GP is necessary even in the case where the patient elects to go private. This is because private health care is not only provided by the 200 or so private hospitals, but also on private patient units in NHS hospitals. There is clearly some degree of competition for scarce resources as private healthcare providers rely to some extent on the infrastructure and resources of the state ones (and vice versa for less serious routine operations, with the NHS using private providers to alleviate waiting lists problems) resulting to a degree of complementarity as opposed to substitutability on the supply side. It should be noted that there have been state attempts to mimic this complementarity in secondary education, by asking private schools to share some of their human resources and infrastructure in the provision of state education.

\section{Supply-side market failures}

Provider-purchaser (p-p) separation and weak market mechanisms. PSMs are often "thin" and can take the form of local or regional markets with a bilateral monopoly or a monopsony. When a local authority commissions services it may face a single provider, or its buyer power may give it monopsonistic power in a local market. It is hoped that a movement from a bilateral monopoly to one where there is plurality of different types of providers will assist with cost discovery that will enable the government to set a fair price (tariff) for the service through benchmarking, as well as providing the market with comparators not only in terms of costs but also in terms of quality. Figure 5 (National Audit Office (NAO) report, 2013: 5) shows the different types of market situation that government may face in PSMs, and the type of interventions that may be necessary to ensure that policy objectives are met.

In some PSMs competition is either set in terms of price and quality as in social care and work placement services, whereas in 


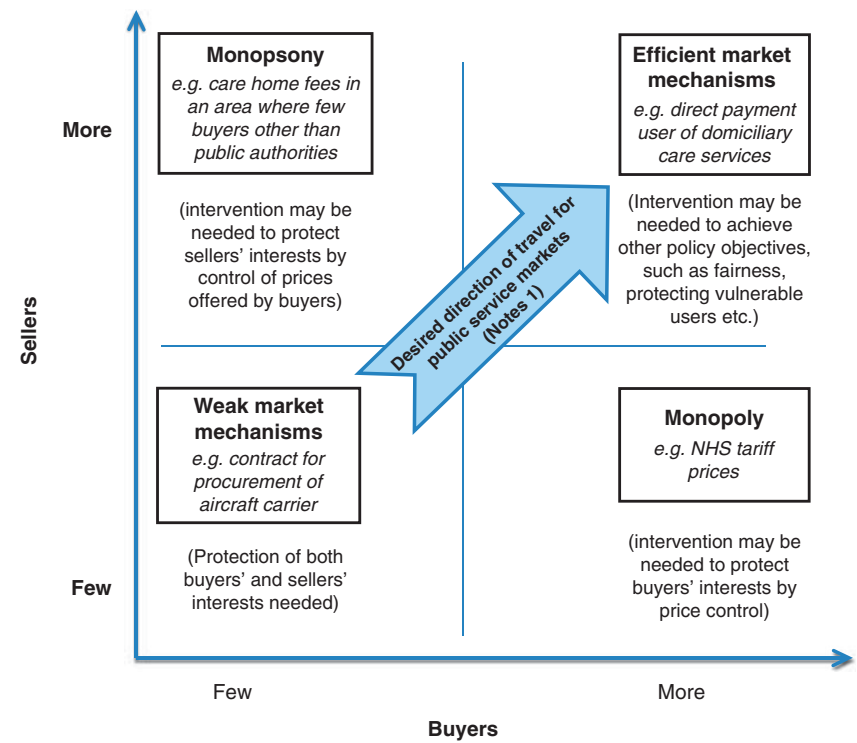

Figure 5 | Different types of market situation in PSMs. Note: Achieved by encouraging new entry, sustaining a range of providers, increasing choice and personalization.

others the government sets a fixed price to providers and asks them to compete in terms of quality when the latter is more difficult to determine (for example, certain types of health care). In both cases the replacement of a bilateral monopoly with that of a monopsony, by introducing plurality on the provision side, will raise issues of finance-ability of the providers as the price set by the commissioning authority will need to sustain supply at acceptable levels as well as ensuring that it is reflective of the cost of provision without adversely affecting quality. Hence as indicated in the north west quadrant in Fig. 5, the existence of a single buyer (for example, in the form of a local authority) may require intervention to ensure the sustainability and continuity of provision by providers as well as their willingness to bid in the next round.

According to the Institute for Government, "Today roughly $£ 1$

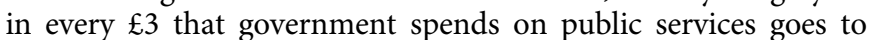
independent providers" (Gash et al., 2013: 4). Separation of the providers from the commissioning side introduces coordination problems and transaction costs in contracting if the product is difficult to define or difficult to verify the value for money and quality of provision. All this is compounded by the dearth of data or inconsistency in data collecting between different LAs. As an alternative the state could provide the service itself either exclusively (effectively eliminating the principal-agent problem), or along with other providers (thus retaining a public sector comparator to the mix). Reputation and some competitive pressure through the existence of comparators may alleviate some of the problems arising from the asymmetry of information between the transacting bodies. As an illustration of the problems, in the case of health, while there was initially hope that nearly all of the NHS contracts would be awarded through competitive bidding, there is now an acceptance that non-competitive contracting is sometimes the best choice if the process is transparent and clearly benefits the patients. ${ }^{8}$

This is strikingly reminiscent of the Swedish health-care experience where separation between $\mathrm{p}-\mathrm{p}$ was put in place in 2003. The split proved ineffective because of a lack of contracting know-how by the purchasers that led to them being dominated by providers due to the latter's greater amount of knowledge and information. Ultimately this led to either the $\mathrm{p}-\mathrm{p}$ split being modified/terminated or a shift of the emphasis over the years in achieving efficiency through collaboration and coordination between local authorities and providers rather than efficiency through competition contracting.

As indicated in Fig. 5, the desired direction of travelling is towards the north east quadrant, where an efficient market mechanism has been achieved with a large number of buyers and sellers. As mentioned in the section "Principal-agent issues", the market for higher education has broadly reached this box as students do pay (through government loans) for their studies and can now shop around as British universities face ever-increasing competition from European universities offering English language degrees. However in England university fees are still capped and the fact that the majority of universities has clustered to the upper $£ 9,000$ fee cup is indicative of a market failure in the form of information asymmetry on the side of buyers (adverse selection) leading to a "market for lemons" where price ends up indicating quality (Akerlof, 1970). In the case of domiciliary care, according the UK Homecare Association (Holmes, 2015), the Care Quality Commission (CQC) has 8,186 registered locations (including people in their own home) where such care is provided. Currently, around $92.1 \%$ of such care is delivered by the independent and voluntary sector commissioned by the local authority (LA), while the remaining is delivered by a LA in-house team. The respective figures in $2008 / 2009$ were $81 \%$ and $19 \%$, respectively, illustrating the growing trend for the independent sector undertaking increasing responsibility for the delivery of such care. The number of adults receiving direct payments for such care in England increased from 107,000 in 2009/2010 to 153,295 (out of a total of 469,725 sate funded by the LA) in $2013 / 2014$, underlying the increasing trend for the direct user of such services exercising choice. ${ }^{9}$

Overall it is difficult to categorize in Fig. 5 what we refer to as compulsory merit goods, as for example offender management services. The first privately managed prison opened in 1992, followed by another eight private prisons by successive governments. In 2004 the National Probation Service and Her Majesty's Prison Service merged to create the National Offender Management Service (NOMS). While NOMS was created incorporating a clear $\mathrm{p}-\mathrm{p}$ split, with the plan of outsourcing offender management (that is, moving into the north west quadrant in Fig. 5 through the introduction of a plurality of providers), such outsourcing slowed down with probation trusts (35 in number, accountable to NOMS) remaining in the public sector and no further expansion of private prisons between 2005 and 2010 (TUC, 2014: 10). Outsourcing has currently resumed with a proposed privatization of $70 \%$ of probation workload. This, however, has been disrupted by the case of two large contractors who have admitted to overcharging the taxpayer for the electronic monitoring contracts to the tune of millions of pounds in fraudulent claims. As prison contracts were held by just three companies, the barring of two from bidding for any new contracts has returned the framework into a bilateral monopoly (back to the south west quadrant in Fig. 5, of a weak market mechanism). As the trusts have only begun commissioning in the last few years, the majority has not much experience in commissioning, procurement and contract management. This is compounded by the fact that it is difficult to measure value added by the provider and also by the fact that reoffending is not only affected by the efficacy of probation services but also by the performance of other services. Finally, the fact that such services are largely affected by the government's ultimate decision making and its coercive authority introduces high policy uncertainty, which largely explains why the repeated attempts to open up such services to competition have failed (Gash et al., 2013). 
Barriers to entry and exit. A lack of contracting capability can be problematic not only on the side of the commissioning authority, but also from the side of the suppliers, which may lead to barriers to entry for smaller inexperienced suppliers. An example of this can be found in utilities regulation concerning the regulatory burden in the supply of electricity and gas. According to the State of the Market Assessment Report (Office of Fair Trading (OFT), Office for Gas and Electricity Markets (OFGEM) and Competition and Markets Authority (CMA), 2014, page 13), the industry is governed by a number of codes. The complexity and costs of compliance is burdensome and can place at a disadvantage smaller suppliers that can ill afford such costs. Similarly, mutuals and other small suppliers may find it difficult to survive once their preferential treatment in being awarded contracts expires and complex licensing/procurement/regulatory structures develop. On the other hand, a continuing preferential setting for smaller firms/mutuals will create a disincentive to grow up, thus creating barriers to expansion (perverse incentives). This is not a novel concern; it features in the market for electricity and gas, where the existence of a size threshold below which a supplier is not required to meet social and environmental obligations may act as a barrier to expansion. On the other hand, Crowe et al. (2014: 6) argue that because of a recent shift to outcome-based contracts of increasing complexity, "public service commissioners $\ldots$ are becoming less connected to smaller and social sector providers" who increasingly depend for their survival on subcontracting or forming partnerships with large private sector partners. We return to barriers to entry, supply competition and ownership structures below.

Natural monopoly characteristics. Natural monopoly characteristics as in the case of hospitals can be viewed a little bit like distribution companies in energy, resulting in regional monopolists. Additionally, both are characterized by asset specificity. It should be noted that in other sectors, such as elderly care, asset specificity is less of a problem; for example, care homes can be transformed into flats. On the other hand, jails cannot. There are also parts of health-care services such as diagnostic services that are characterized by very large capital costs. In such cases it may be appropriate for family doctors (GPs) to lease such services by a single provider who owns the equipment. Box 3 illustrates some of these issues for health-care services.

If a market can only support one or two providers, "competition in the market" is unlikely to work effectively. Moreover, the same factors that make these markets thin in the first place can often create significant barriers to entry, meaning competition for the market is not feasible either. ${ }^{10}$ In some cases you may in fact end up with a bilateral monopoly, with a single commissioner negotiating with a single provider. ${ }^{11}$ This leads to

\section{Box 3 | Barriers to entry in health-care markets}

For many health-care services, the provider side of the market is likely to be very "thin" in many parts of the country. This happens for multiple reasons:

The geographic market for many health-care services is quite narrow. Patients are unwilling to travel 500 miles for GP appointments (although they may be willing to do so for specialist treatment).

Many services have very high fixed costs (radiotherapy machines cost millions of pounds).

Many services (such as A\&E Departments) have large economies of scale or scope, possibly even rising to the level of natural monopoly.

In rural areas demand is sparse, reducing the number of providers that can be supported. the usual inefficiencies that come with bargaining. A solution is to treat such cases as we treat infrastructure bottleneck facilities in utilities: by price regulating for fair access to the use of such services by GPs (the equivalent of transmission and distribution access prices).

Supply competition, ownership structures and exit. Exit in PSMs creates the problem of who takes over (for example, failing sixth-form colleges). What happens to consumers facing failing providers if there are no other providers in the market? As mentioned this may give rise to moral hazard issues that can be exploited by a provider to demand a bail out or additional funding and in this way damage UK's efficiency incentives by removing the threat of exit from the market as a punishment for inefficiency. For example, in 2011 the UK social care sector only survived the potentially disorderly exit of the largest care bed provider as a result of considerable effort by a number of organizations and individuals, without formal processes and powers to call upon to ensure an orderly exit (Department of Health, 2013).

Public services such as health, social care and education are essential to many people's lives, which require government to ensure arrangements are in place to maintain continuity of service in order that harm or detriment to users is avoided (such as reduced educational outcomes, or physical harm or even death in the case of health or care), and policy objectives are met. Public authorities must ensure that arrangements exist to guarantee service continuity in the event of provider failure or exit. For this reason, effective oversight in public services can require government to monitor the financial health of key providers to assess the degree of risk that exists in the market to service continuity for users.

Government has to avoid, however, providing explicit or implicit guarantees to support providers that fall into financial difficulties, for this could risk weakening the incentives on providers to manage their own businesses and maintain their financial viability. The government therefore has to balance the need for poorly performing providers to exit the market with the need to protect users by ensuring continuity of service.

Does ownership structure matter in outcomes? The emergence of mutuals may deliver better outcomes for their customers as by the very nature of their ownership such firms overcome asymmetric information problems. In contrast, shareholderowned firms will promote the interests of their managers as well as the shareholders and will typically take advantage of the asymmetric information on the side of the users/purchasers. Similarly, owner managed companies will go for profit maximization; if they know that their customers are unable to discern quality (in the short term anyway) then again there is little prospect of the provider being punished for providing poor service, thus dampening exit pressures (for example, barriers to exit).

\section{Overseeing PSMs}

Rules for ensuring a competitive market. Like private markets, PSMs need rules that govern competition in the market and these rules need to be enforced where appropriate. Competition law that prohibits anticompetitive behaviour (or practices) applies to all private sector providers operating in PSMs. It should also capture, in most circumstances, not-for-profit providers and publicly funded providers that operate in similar markets. However, it is less clear whether it applies to public sector buyers (where they do not act as providers in the same market). Public bodies should also bear in mind that their conduct may also (or alternatively) be subject to other laws within the field of 
competition law, including public procurement, merger control and state aid laws.

Competition powers may be an imperfect tool for publicly funded providers. The Competition Act is largely untested in PSMs. It is unclear to what extent competition bodies would pursue the full force of enforcement action against publicly funded providers that infringe competition law. Enforcement action that leads to financial penalties being imposed on a public body for a breach of competition law are likely to have to be met from the budget of the public body; this could in turn impact adversely on the level of public services available to users. However if the competition body decides not to pursue enforcement action against a publicly funded provider this could create tension with other priorities or principles that competition bodies pursue:

- Equal treatment: The competition authority risks being seen as treating providers unequally if, in similar circumstances, it proceeds against private providers with the full rigour of competition law but publicly funded providers do not suffer similar sanctions. In addition, such a scenario could lead to a "chilling effect", which makes private providers less willing to invest and engage in the market.

- Deterrence: Similarly, the deterrent effect will be lost if competition authorities do not take enforcement action against providers who infringe the law, which may risk giving misleading signals to other publicly funded providers in the market that they too may not face enforcement action if they transgress.

However, in guidance issued by the (former) Office of Fair Trading $^{12}$ to public bodies on applying competition law, it emphasizes that a level playing field and a similar commitment to compliance should exist in those markets, particularly in mixed markets in which public bodies engage in economic activities, alongside private firms and third-sector organizations (OFT, 2011a, Paragraph 4.2). It makes clear that where competition law does apply to a public body it could potentially expect to face adverse consequences such as reputational impact; the possibility of financial penalties and or civil claims for damages (OFT, 2011a, Paragraph 4.8-4.9).

This gives an indication of some of the types of considerations that competition bodies are required to balance when they consider applying competition law in relation to public bodies acting as providers in PSMs. It is therefore important that government works with the competition authorities to help raise awareness of the conditions under which competition rules could apply to public bodies' involvement in the public services markets they oversee. This could include outlining and illustrating the types of behaviours and practices that should be avoided.

This still leaves the question of how the government and competition authorities should deal with public sector buyers who are not captured by the provisions of competition law but potentially abuse their market position. The guidance suggests that in response to competition concerns in a PSM (which may or may not be captured by the provisions of the Competition Act) the competition authority may decide to use its tools flexibly and apply a range of measures; for example, advocacy work to help raise awareness, or a study to explore competition issues arising in that market such as the impact of public bodies' buyer power on the sustainability of provision (OFT, 2011a, Paragraphs 4.10-4.11).

Alternatives to competition powers to mitigate buyer power of public bodies: ombudsman and dispute resolution schemes. Where competition law is not deemed to apply to a public body that has buyer power (or it is unclear if the law applies), an alternative approach can be for the provider to invoke a dispute resolution clause in their contract with the public body, particularly if this refers to mediation or alternative dispute resolution. Both are generally far cheaper than going to court and should allow the parties to continue to engage in a commercial relationship. In various sectors of the economy statutory provision for a form of alternative dispute resolution already exists:

- In the communications markets covered by the Communications Act 2003, disputes on matters not covered by competition law or in the scope of other regulatory or legal powers, communications providers can raise a regulatory dispute that requires the regulator (Ofcom) to use its regulatory powers to resolve.

- An adjudication scheme has also been set up to cover the groceries market, and in particular the buyer/supplier relationship. The job of the independent groceries code adjudicator is to judge disputes between the suppliers and supermarkets (that is, buyers with market power) where unfair, or abusive, treatment is alleged.

- In financial services, provision is additionally made for smaller businesses (as well as consumers) to complain to the Financial Ombudsman Service if they feel they have been treated unfairly, and if upheld, they can order the complainant to be compensated for their loss.

An EU directive on Alternative Dispute Resolution schemes that are available to help complainants resolve their dispute outside court is currently being consulted on by the UK Government. If parties to a dispute are unable to settle their differences, ADR offers a quicker and cheaper means of resolving that dispute. Ombudsman schemes already exist as a back-stop for service users of local government and the NHS where existing complaint-handling processes have not resolved the problem to the satisfaction of the user. While PSMs are out of the scope of this EU directive, in principle consideration could be given to setting up similar dispute resolution schemes as an avenue of potential redress for providers of public services who are in dispute with commissioners, as a way of providing quick and cheap resolution (instead of having to take matters through the courts).

Other key requirements for effective PSMs. As public services are "merit goods" the state requires these services are universally available to all those deemed eligible for them, as the benefits of mandating their provision on a free and universal basis for society as a whole is deemed to outweigh the costs of their provision to the taxpayer. To meet these public policy objectives, government also has in place rules and or financial incentives that sit alongside regulation of markets by competition law. These rules may, for example, be intended to ensure minimum standards or equity in provision, or to discourage certain types of discriminatory practice by market participants.

Alongside universality and equity, the protection of the vulnerable is another key concept in the provision of public services. The characteristics and often complex nature of public services (discussed elsewhere in this article), together with the vulnerability of many service users, requires government to establish independent regulatory frameworks for public services delivery. These comprise initial accreditation or licensing of providers, and a monitoring and inspection regime to ensure that quality standards are being upheld. An independent accreditation or licensing regime is intended to ensure that only providers that meet required national standards are allowed to enter the market, or stay in the market. Independent inspection regimes monitor, 
inspect and regulate providers to ensure their services continue to meet required standards, and take remedial action or withdraw the licence if a provider fails to do this. In education, Ofsted performs the role of independent quality regulator, and in health care and social care this role is led by the CQC.

Enabling users to participate actively in the market. As in other consumer markets, a lack of good information and advice can act as a barrier to an effectively functioning market. In PSMs where user choice is the means of service allocation, government can help create the conditions for an efficient market by enabling users to participate actively in the market. Users need access to good-quality information to inform their choice, as well as help to assess it. They also need to be able to feel they can act on their choice. This means enabling users to switch providers if they wish (without causing them undue distress and inconvenience), as well as ensuring effective means of redress exist for users who experience poor-quality or inadequate provision.

Dimensions of information for users. As explained earlier, public services have unusual characteristics that can inhibit the ability of users to make effective choices. These can be intrinsic to the type of service; in the case of "experience" or "credence" goods the outcomes for the user can be largely unknown in advance, making it difficult to make a well-informed choice. Some public services are by their nature complex and information on quality and outcomes may be unsatisfactory from a user's perspective for any number of reasons: incompleteness; difficulty in its interpretation, or in its comparability; not covering all aspects of relevance to the user.

The various ratings and user-experience feedback surveys in the higher education sector have developed and been refined over a number of years, and provide prospective students with a rich resource of information. Nevertheless such user information has to be managed, interpreted and presented properly if users are to benefit from it. The energy market is an example of where consumers can become easily confused by the plethora of information on different rates available, which can reach a tipping point where the market is no longer working in the interests of consumers. Various market solutions have emerged to help consumers navigate the plethora of tariffs and find the best deals for their energy needs. The government has reduced drastically the number of tariffs available in an attempt to deal with this "confusopoly" problem (Hviid and Waddams-Price, 2012; Siciliani, 2014), but this is likely to reduce competition in the market by increasing the ability of providers to price coordinate. In health care, attempts to create tools to inform user choice have been less systematic and are a lot less well developed to date. The recent Friends and Family test introduced post-Francis Report is an attempt to introduce a more systematic approach to provide potential users with a better idea of past users' experiences of the health care they received at a hospital.

Owing to its specialist nature, however, patients are likely to need to rely on the advice and support of health-care professionals to ensure they receive appropriate treatment and can effectively navigate the system. Health care is not the only public service where users may require the advice and support of an intermediary. Social care users can benefit from the expert advice and support in tailoring a suitable package of care to meet their needs. However, the incentives on professionals in the "system" may not always converge with the interests of the user. For example, a GP may have to balance the wishes of the user for an expensive course of treatment or package of care, with pressures on their Practice budget, and the wider interests of the taxpayer. For these reasons and others (such as fitting in with existing local commissioning arrangements), professionals may feel constrained in the choices they are prepared to offer patients, and more likely to default to existing care patterns and pathways unless otherwise prompted by the patient or their advocate.

However in some areas, for example social care, personal budget holders may have access to alternative sources of advice that can help support them in deciding how to meet their individual care needs. User-led organizations (some of these have been spun-off as social enterprises from the public sector), independent brokers and those who offer peer-support can offer advice, support and advocacy to users that is independent of the "system". The (former) OFT found in research it carried out on so-called "choice tools" that qualitative feedback on consumer experience can help make complex decisions and comparisons easier for users (OFT, 2011b). ${ }^{13}$

Consumer redress. While the national quality regulators (such as Ofsted and CQC) provide service quality oversight, strong PSMs also need effective redress mechanisms that enable individual users who have experienced poor service, or are dissatisfied, to complain and obtain a satisfactory response. This is particularly so given the essential nature of these services and the inherently complex, experiential and personal features of some of these types of services (discussed earlier in this article). These features make it more difficult for users to make well-informed decisions in the first place about which provider to choose, and also can present barriers to switching provider making it very inconvenient and disruptive for the individual to switch. Redress mechanisms are also an area where good information and advice can play a key role as it allows users to have a better idea of the standards they have a right to expect and how they can raise concerns (Which?, 2014).

In addition, also discussed earlier, some PSMs have geographical constraints, which can be a key determinant in defining the local market from the perspective of users who live in an area. Typically there may be a limit to the choice of local hospitals, schools and so on, or, as in some areas and for some services, no effective choice. If the local market lacks real competitive pressures and genuine choice, and switching is not a realistic proposition for many users in an area, the accessibility of effective redress is vital. Otherwise users may have little prospect of proper redress if the services they receive are substandard and need improving.

Current research from the United Kingdom shows a general lack of understanding about the role or importance of redress mechanisms in public markets. For example, recent research by the UK consumer organization Which? found that services are poorly organized, leading to a "complaints maze" that consumers find hard to navigate. Which?'s survey of consumers who had experienced a problem with public services found that over a third did not complain, and over half of those did not take their problem further following a first complaint. The main reasons cited were: scepticism that their complaint would have any impact; a lack of understanding of the complaints process; and fear of repercussions for the quality of ongoing services where there was a personal relationship between complainant and provider. Clearly there are some significant impediments to this element of PSMs working effectively.

\section{Promoting healthy competition between providers}

Diversity of providers and a level playing field. PSMs typically have a range of different types of provider. ${ }^{14}$ In some sectors (for example, hospitals, schools, higher education institutions), the publicly funded providers still represent the norm, while 
"not-for-profit" and "for-profit" providers are largely marginal participants in such markets. In some markets such as social care, the situation is almost the opposite; publicly funded providers are scarce (most local authorities are no longer involved in direct provision any more) and private or not-for-profit providers represent the bulk of provision in most areas. In other markets such as nursery and childcare education, the picture is mixed with a more even split between public and private providers.

Some of the factors that the (former) OFT guidance has identified as acting as barriers to a level playing field between providers are differences in regulation, taxation and pensions treatment between different types of provider; incumbency advantages enjoyed by existing firms, such as access to information, pre-qualification and bid criteria, and transition costs; and a lack of clarity in the application of competition law (covered earlier in this article). Where barriers do exist the position of incumbents may be strengthened and reduce the level of competition and choice in the market.

Entry, expansion and exit of providers. Research shows (CMA, 2015) that in private markets at least half of the increase in productivity over time arises from the exit of less productive firms and the entry of new and more productive firms (for example, Disney et al., 2003). New providers that enter the market may offer a different, innovative service or provide a service that better meets particular needs. Competition from new entrants can also act as an incentive for existing providers to drive up the quality of their service or face exit (Harris and Li, 2008; Bloom and Van Reenen, 2010).

In some PSMs, potential new entrants may face difficulties trying to enter the market. For example, small providers may be deterred by what they perceive as disproportionate requirements to meet existing accreditation and regulatory criteria. New entry and countering barriers to entry may be achieved, however, through a variety of means:

- spinning services out of the public sector to create new providers in the market, and

- encouraging new entrant providers by setting prices for public services that are neither too high (wasting taxpayer's money), nor too low such that they would discourage providers from entering the market (and also potentially risk reducing the quality of existing provision).

PSMs may only offer weak financial incentives to expand that act as a break upon strongly performing providers' willingness to take over failing providers, or create new capacity. Funding constraints can also lead to difficult trade-offs between creating supply-side flexibility (potentially important, for example, in making competition effective between schools in an area), and controlling public spending during periods of tight budgetary constraint.

The regulatory context itself, with its restrictions and incentive arrangements imposed on users' choices and providers, respectively, may act to restrict choice and competition in PSMs as has happened at times and for various reasons in the regulated utilities. For example, in the case of registration choices for patients of GP services, until recently users were allowed only one choice from GPs close to their residence (and possibly close to their place of work). This precludes the ability of users to shop around for GP services (which in theory would equate to alternative providers competing for patients) in neighbouring boroughs. In addition, GPs are paid by the number of people registered with them, irrespective of how frequently patients are using the practice or the quality of the service that patients receive when they do. These arrangements lacked incentives for an efficient functioning market as choice and incentives for competition among GP practices were limited. ${ }^{15}$ Similarly, the establishment of catchment areas for schools may reduce competition between neighbouring schools once again restricting both choice by parents and competition among schools.

Competition in public services is more likely to be effective if the incentives for providers are strong, rewarding success and penalizing poor performance. The risk of going out of business can act as a powerful incentive on providers to perform well. Certain types of public service such as social care have a wellestablished private sector and third-sector provider base that represent the vast majority of provision in the market. Most care providers in the market are small and individually they may exit their local market without causing significant disruption. In principle, the closure of poorly performing providers is possible and does sometimes occur in other public services like schools and hospitals; however, in reality this is unlikely to happen if it leaves the needs of the local population in the area inadequately provided for.

Common approaches to dealing with poorly performing state providers, particularly in health and education, is either to replace the existing management or to allow another provider to merge with or take over its running. It is also necessary to bear in mind that the exit of a provider may not always be caused by poor management; it could be partially or wholly due to the need for a more fundamental service re-configuration, such as the consolidation or rationalization of existing providers in the local area. In these circumstances, replacing the leadership of the school or hospital (etc.) is unlikely to provide an effective solution.

Service continuity. Public services such as health and social care are essential to many people's lives and well-being. Hence, it is unacceptable from both an individual and societal perspective for other types of public services, such as education or probation services, to be disrupted for any length of time. Government's statutory duties require it to ensure that there is continuity of these services, and to keep service disruption where it does occur to a bare minimum. Government, however, wishes to avoid providing explicit (or implicit) guarantees to support providers that fall into financial difficulties. If not, there is the risk of "moral hazard" that a government guarantee would weaken the incentives on providers to manage their own businesses effectively and maintain their financial viability, if they knew government would step in and bail them out if they got into financial trouble. Therefore, the government has to find a way to balance the need for poorly performing providers to exit the market with its duty to ensure service continuity and protect users from service disruption. Both the financial crisis in 2008 that led to the UK's worst banking crisis (defining public services in the broadest sense to include bank accounts), and the Southern Cross Health care debacle in 2011 revealed an important feature of markets in public services, where service provision is in real danger of severe disruption the state has to step in and in extremis it becomes the "provider of last resort".

In some sectors of the economy there are continuity arrangements and formal mechanisms for oversight of a provider's financial "health" at the national level. These sectors include travel (aviation and tour operators), energy, rail and health. The failure of Southern Cross demonstrated the risk a major business failure can pose to both the quality of care that people receive and to the continuity of those care services. It also led to significant concern and distress among the people receiving services, their families and carers. In the event the risk to the continuity of care was largely managed but this outcome was not a forgone conclusion and was the result of considerable effort by a number of organizations and individuals, without formal processes and 


\section{Box 4 | Service continuity in social care}

In the social care market, where there are many small providers, it is clear that when these providers exit or face closure, the local authority has a responsibility to talk to local providers and to work with them if they decide a service must close to ensure that people are given the necessary support to arrange alternative care. However, there are a number of medium and large providers of care, operating across large parts of the United Kingdom, on a significant scale. The impact of such a provider failing would affect many parts of the country and it is not reasonable to expect individual local authorities to manage the situation. National coordination and oversight is needed. Keeping abreast of the commercial negotiations that occur if a major company has to be wound up cannot be done effectively at the local level. The Government's consultation in 2013 on oversight in adult social care recognized the strong need for a regulator to take on the role of overseeing those care providers whose services, for whatever reason, would be hard to replace if failure occurred.

powers to call upon. As a result it convinced Government that adult social care should also have formal mechanisms in place to ensure service continuity for all social care users (Department of Health, 2013).

An oversight system to capture early warnings where a large or difficult-to-replace provider is facing financial difficulties, and to take action to stop the situation deteriorating, are an important feature of public service continuity regimes. Box 4 provides an illustration of the oversight regime in social care at the local level, and the proposed national oversight regime.

Ensuring the market is delivering the public policy objectives. Using markets to deliver public services does not mean that government's responsibilities for achieving policy objectives costeffectively are diluted. Yet market delivery involves provision by non-public sector entities, which are not directly accountable to government or the taxpayer. This lack of influence means that government must design the legislative framework of rules for the market, monitor its overall financial sustainability and ensure that system-wide the provision of public services is effective, value for money and achieving government's policy objectives.

According to the NAO Report, 2013, to fulfil this systemic role government must be prepared to:

- Monitor and intervene, where appropriate, to calibrate central funding, depending on the national balance of supply and demand, and taking account of the patterns of regional variation (and levels of spare capacity).

- Assess the likely impact of policy reforms and possible future scenarios in terms of their likely impact on policy objectives.

- Develop an understanding at the national level of the market structure, including market size and concentration levels, as well as the degree of exposure to publicly funded users, price and quality variations and trends, rates of entry and exit, and significant merger and acquisition activity.

- Work with the competition authorities and relevant quality and sector regulators, to raise awareness, standards and enforce rules and the right market behaviour.

Departments that have oversight responsibilities for market delivery of public services may also consider adopting a presumption that they should actively review the delivery of public services through market mechanisms on a periodic basis. Such a review could be undertaken by or in consultation with the Competition and Markets Authority, or in the case of NHSfunded health care, with Monitor. If the results of the review suggest that significant user detriment exists, government may need to decide on appropriate remedies or be prepared to consider referral of the market for more detailed investigation. Ultimately if a PSM fails, it will be the state who retains the role as "provider of last resort".

\section{Conclusions}

Given that the newly constituted competition authority in the United Kingdom, the CMA, now has an obligation to oversee the development of competition and consumer choice in PSMs, and the UK's NAO has been working on developing an analytical framework for evaluating whether such markets provide value for money for the taxpayers when auditing such markets, our article is a first step into providing a conceptual economic framework for analysing and evaluating PSMs.

The policy of delivering public services by creating quasimarkets still indicates the need for large doses of costly intervention irrespective of whether such markets take the form of a monopsony, a monopoly or a more efficient market mechanism as described in Fig. 5. Our article considered the current situation and attempted to identify the desired way forward by looking at different types of public services. We have identified two issues for further development and research. First, the United Kingdom needs to develop an institutional setup that will ensure that such markets are properly overseen, are subjected to competition rules and/or alternative resolution mechanisms (where appropriate) to protect sellers and/or buyers, and that the objectives of universality and equity in provision as well as the protection of the vulnerable are met in the provision of such services, as well as the arrangements for the continuity of service. The framework should also ensure healthy competition in or for the market with users enabled to effectively participate by being given information and consumer redress in the former case, or through the development of commissioning and contracting skills in procurement in the latter case. The costs that such a set up indicates is more than offset in the case of choice merit goods through the benefits that the introduction of competition brings into the market through innovation, value for money services and increases in productivity that the promotion of healthy competition and choice brings through. Second, the $p-p$ split that is part of the transformation into a quasi-market introduces a market failure through the creation of a principal-agent relation where the commissioner no longer produces in-house. In the case of compulsory merit goods it is unclear how the transaction costs this transformation introduces are offset by the introduction of choice and competition since the former is not desired and the latter is not always relevant or achievable. The introduction of competition through a quasi-market format may introduce some efficiencies; however, it clearly involves the re-invention of the system for the benefit of the creation of an internal market in the hope of raising cost efficiency and/or improvement in the quality of provision. However, the social value of such services, even if not profitable, is reflected in the form of large externalities and often a universal service obligation that essentially has historically meant the need for involvement of local voluntary and charity organizations in the provision of such services. It is not clear that as things stand these locally based providers will be willing to provide cost-free services for the benefit of profit-making providers.

\section{Notes}

1 Intervention to correct market failures is distinct from intervention by competition authorities to prevent companies from taking advantage of users' behavioural biases such as loss aversion, hyperbolic discounting and status quo bias (framing). Such biases arise in many types of markets (most notably financial services), including 
PSMs. This leads to the need to carefully design public policy and an institutional framework that addresses such biases (see Barr et al., 2013; Manski, 2013).

2 The majority of modern industrial organization textbooks discuss market definition both in a theoretical context as well as in practice; the most comprehensive book to date on this method of analysis (used in practice by all competition authorities across the developed and developing world) is by Motta (2004).

3 For a closer analysis on merit goods, externalities and market failures, please refer to any microeconomics or industrial organization textbook (for example, Griffiths and Wall, 2000).

4 As mentioned earlier, education to the age of 16 and some health services (for example, vaccinations) are not optional. However, they do not belong to this second category as they are consumed by "all" rather than a minority.

5 Pissarides (2014) argues that it is the services themselves that should be free or subsidized, as in Scandinavian countries, rather than the users through transfers of money to families.

6 This double agency issue is also referred to in Van Stolk et al. (2010), where providers are expected to act as agents of both patients and payers. The shifting of the responsibility for commissioning care to GPs has given rise to questions concerning the commissioning skills, capacity and incentives of GPs to ensure value for money for both their patients and the taxpayers (see Crowe et al., 2014).

7 Notably, the UCAS admissions system is currently changing its rules to allow UK students to apply to European universities when these meet equivalent standards to those in the United Kingdom (Coughlan, 2015).

8 See Crowe et al. (2014), Gash and Panchamia (2013),Gash et al. (2013) on contracting in PSMs. Dranove and Satterthwaite (2000) discuss the importance of looking at supply-side issues such as entry, exit and monopolistic competition in health-care markets. Forder and Allan (2011) look at competition in the UK care homes market and analyse whether cross-subsidization and/or market segmentation result from the existence of two groups of users: individual self-payers and local authority funded ones.

9 According to the Care Act (2014), as of April 2015 all eligible people have a right to request to receive such a direct payment.

10 Competition for the market has been used extensively in the United Kingdom, for example in rail services, the national lottery and local bus services, to name but a few examples. Potential providers compete to win franchises (contracts) to operate in particular areas or provide particular services.

11 This happened in the case of prison contracts, as we discuss in the section "Providerpurchaser $(p-p)$ separation and weak market mechanisms".

12 The OFT and the Competition Commission were recently merged. The new body, CMA, took up its powers in 1 April 2014.

13 According to Mays (2013), the least problematic of the recent reforms in health, and to some extent the most cost effective, has been the introduction of personal health budgets.

14 Private and social sector or charity providers competing for the right to provide, thus making the market contestable (for example, Julius, 2008, 2013).

15 For a full analysis and annotated bibliography of provider incentives in health care in OECD countries, see Van Stolk et al. (2010).

\section{References}

Akerlof GA (1970) The market for "lemons": Quality uncertainty and the market mechanism. The Quarterly Journal of Economics; 84 (3): 488-500.

Barr M, Mullainathan S, Shafir E (2013) Behaviorally informed regulation In: Shafir E (ed) The Behavioral Foundations of Public Policy; Chapter 26, Princeton University Press: Princeton, NJ.

Bloom N and Van Reenen J (2010) Why do management practices differ across firms and countries? Journal of Economic Perspectives; 24 (1): 203-224.

Bradley S and Taylor J (2002) The effect of the quasi market on the efficiencyequity trade off in the secondary school sector. Bulletin of Economic Research; 54 (3): 295-314

Bradley S and Taylor J (2010) Diversity, choice and the quasi-market: An empirical analysis of secondary education policy in England. Oxford Bulletin of Economics and Statistics; 72 (1): 1-26.

CMA. (2015) Productivity and Competition. Competition and Markets Authority, CMA45: London.

Coughlan S (2015) UCAS admissions system to include European universities. BBC News, http://www.bbc.co.uk/news/education-31503193, accessed 1 November 2015.

Crowe D, Gash T and Kippin H (2014) Beyond Big Contracts. Institute for Government: London.

Dassiou X, Langham P, Nancarrow C, Scharaschkin A and Ward D (forthcoming) New development: Exploring public service markets. Public Money and Management, in press.

Dassiou X, Langham P, Nancarrow C, Scharaschkin A and Ward D (2015) Public service markets: Their economics, oversight and regulation, Social Science Research Network. Available at: http://papers.ssrn.com/sol3/papers.cfm? abstract_id $=2538532$, accessed 12 July 2015.

Department of Health. (2013) Oversight in adult social care. The Consultation Response, May: 5.
Disney R, Haskel J and Heden Y (2003) Restructuring and productivity growth in UK manufacturing. Economic Journal; 113 (489): 666-694.

Doetter L and Götze R (2011) Health care policy for better or for worse? Examining NHS reforms during times of economic crisis versus relative stability. Social Policy \& Administration; 45 (4): 488-505.

Dranove D and Satterthwaite M (2000) The industrial organization of health care markets In: Culyer AJ and Newhouse JP (eds) Handbook of Health Economics, Volume 1; Chapter 20, Elsevier Science: Amsterdam, The Netherlands.

Fletcher A (2013) Privatisation, economic regulation and competition in the utilities: Have we got the balance right? Beesley Lecture Series Speech, Institute of Directors: London.

Forder J and Allan S (2011) Competition in the care homes market; a report for the OHE commission on competition in the NHS [pdf]. Office for Health Economics: London. Available at: https:/www.ohe.org/sites/default/files/ Competition\%20in\%20care\%20home\%20market\%202011.pdf, accessed 9 June 2015.

Gash T and Panchamia N (2013) When to Contract: Which Service Features Affect the Ease of Government Contracting? Institute for Government: London.

Gash T, Panchamia N, Sims S and Hotson L (2013) Making Public Service Markets Work. Institute for Government: London.

Gaynor M, Moreno-Serra R and Propper C (2012) Can competition improve outcomes in UK health care? Lessons from the past two decades. Journal of Health Services Research \& Policy; 17 (Suppl 1): 49-54.

Glennerster H (1991) Quasi-markets for education? The Economic Journal; 101 (408): 1268-1276.

Griffiths A and Wall S (2000) Intermediate Microeconomics: Theory and Applications. 2nd edn. Pearson Education Limited: Harlow, UK.

Harris R and Li QC (2008) Evaluating the contribution of exporting to UK productivity growth: Some microeconomic evidence. The World Economy; 31 (2): 212-235.

Holmes J (2015) An Overview of the Domiciliary Care Market. United Kingdom Home Care Association: Wallington, UK.

Hviid M and Waddams-Price C (2012) Non-discrimination clauses in the retail energy sector. The Economic Journal; 122 (562): F236-F252.

Julius D (2008) Public Services Industry Review-Understanding the Public Services Industry: How Big, How Good, Where Next?. Department for Business Enterprise and Regulatory Reform (Predecessor of BIS-Department for Business, Innovation and Skills): London.

Julius D (2013) Private companies can provide a public service, Financial Times Comment 14 July. Available at: http://www.ft.com/cms/s/0/61e40394-eae411e2-bfdb-00144feabdc0.html\#axzz3bWb3PwvT, accessed 29 May 2015.

Le Grand J (1991) Quasi-markets and social policy. The Economic Journal; 101 (408): $1256-1267$.

Lubienski C (2009) Do Quasi-markets Foster Innovation? A comparative perspective. OECD Education Working Papers No. 25, OECD Publishing: Paris.

Manski C (2013) Public Policy in an Uncertain World. Harvard University Press: Cambridge, MA.

Mays NB (2013) Evaluating the labour government's English NHS health system reforms: The 2008 Darzi reforms. Journal of Health Services Research \& Policy; 18 (2 Suppl.): 1-10.

Motta M (2004) Competition Policy: Theory and Practice. Cambridge University Press: Cambridge, UK.

NAO. (2013) Deciding Prices in Public Service Markets: Principles for Value for Money. National Audit Office: London.

OECD. (2015) Teaching staff (indicator). https://data.oecd.org/eduresource/teach ing-staff.htm\#indicator-chart, accessed 22 September 2015.

OFT. (2011a) Public Bodies and Competition Law: A Guide to the Application of the Competition Act 1998. Office of Fair Trading, 1389: London.

OFT. (2011b) Empowering Consumers of Public Services Through Choice-Tools. Office of Fair Trading, 1321: London.

OFT, Ofgem and CMA. (2014) State of the Market Assessment Report. Ofgem: London.

Pissarides C (2014) Social Europe in a climate of austerity. Available at: http:// www.socialeurope.eu/2014/06/social-europe-austerity/, accessed 4 June 2015.

Propper C (1995) Agency and incentives in the NHS internal market. Social Science \& Medicine; 40 (12): 1683-1690.

Propper C (2012) Competition, incentives and the English NHS. Health Economics; 21 (1): $33-40$

Propper C and Venables M-A (2013) An assessment of labour's record on health and healthcare. Oxford Review of Economic Policy; 29 (1): 203-226.

Propper C, Burgess S and Gossage D (2008) Competition and quality: Evidence from the NHS internal market 1991-1996. The Economic Journal; 118 (525): 138-170.

Propper C, Burgess S and Green K (2004) Does competition between hospitals improve the quality of care? Hospital death rates and the NHS internal market. Journal of Public Economics; 88 (7-8): 1247-1272.

Siciliani P (2014) Confusopoly and the fallacy of behaviouralism-A response to professors Littlechild and Hviid/Waddams price. European Competition Journal; 10 (3): 419-434.

TUC. (2014) Justice for Sale-The Privatisation of Offender Management Services. Trade Union Congress: London. 
Van Stolk C, Bjornsson G and Goshev S (2010) Provider incentives in social protection and health, WR-799-WB; Rand Europe working paper series: Cambridge, UK.

Which? (2014) The Care Maze: The challenges of navigating care for older people. Section 3. Available at: http://conversation.which.co.uk/energy-home/arranging-care-support-for-older-family-members/, accessed 12 June 2015.

\section{Data Availability}

Data sharing not applicable to this paper as no datasets were generated or analysed during the current study.

\section{Additional Information}

Competing interests: The authors declare no competing financial interests.

Reprints and permission information is available at http://www.palgrave-journals.com/ pal/authors/rights_and_permissions.html

How to cite this article: Dassiou X, Langham P, Nancarrow C, Scharaschkin A, and Ward, D (2015) Public service markets: their economics, institutional oversight and regulation. Palgrave Communications. 1:15035 doi: 10.1057/palcomms.2015.35.

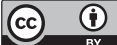
International License. The images or other third party material in this article are included in the article's Creative Commons license, unless indicated otherwise in the credit line; if the material is not included under the Creative Commons license, users will need to obtain permission from the license holder to reproduce the material. To view a copy of this license, visit http://creativecommons.org/licenses/by/3.0/ 